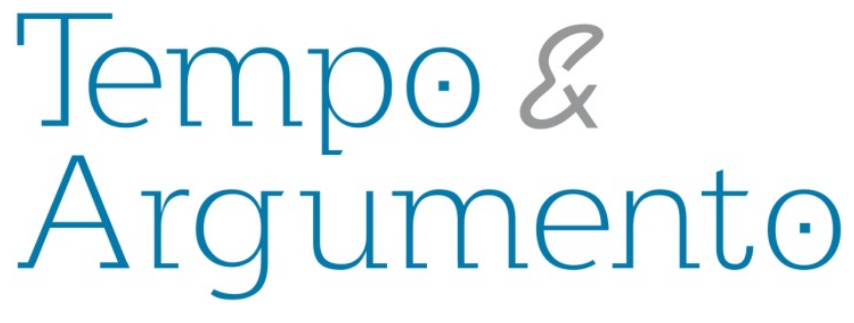

\title{
A internet, um novo espaço de disputa pela memória da ditadura militar no Brasil
}

\begin{abstract}
Resumo
A pós-modernidade que, a priori parecia ter lançado a História no campo da irrelevância, acabou por desencadear um movimento de valorização da memória. No Brasil, a aprovação do $3^{\circ}$ Plano Nacional de Direitos Humanos (PNDH-3, 2010) transformou essa tendência em política pública, ao adotar como um de seus eixos norteadores o "Direito à Memória e à Verdade". Esta iniciativa governamental, aliada ao novo paradigma da comunicação, acirrou uma disputa em torno da construção da memória coletiva sobre o período da Ditadura Militar no Brasil, transformando a internet em palco privilegiado desse embate. A importância do tema deriva da compreensão da memória enquanto fator de coesão e de afirmação de valores; transformada em discurso, a memória pode influenciar o comportamento social e interferir no exercício do poder. Desse modo, analisando dois sites representativos, pretendemos resgatar os valores em torno dos quais cada grupo procura sustentar a 'sua' verdade e interferir na construção da memória nacional.
\end{abstract}

Palavras-chave: Memória. Comunicação. Poder. Internet. Ditadura Militar - Brasil. Brasil - História (Período Militar).

\section{Sonale Diane Pastro Oliveira}

Mestra em Ciências Humanas e Sociais pela Universidade Federal do ABC/UFABC. Graduada e Licenciada em História pela Universidade de São Paulo/USP.

sonale.pastro@gmail.com

\section{Maria Gabriela S. M. C. Marinho Doutora em História Social pela \\ FFLCH/USP. Professora e pesquisadora da Universidade Federal do ABC/UFABC - Centro de Engenharia, Modelagem e Ciências Sociais Aplicadas, Santo André, São Paulo. \\ gabriela.marinho@ufabc.edu.br}

\section{Para citar este artigo:}

OLIVEIRA, Sonale Diane Pastro; MARINHO, Maria Gabriela S. M. C. A internet, um novo espaço de disputa pela memória da ditadura militar no Brasil. Revista Tempo e Argumento, Florianópolis, v. 5, n.10, jul./dez. 2013. p. $159-181$.

DOI: $10.5965 / 2175180305102013159$

http://dx.doi.org/10.5965/2175180305102013159 


\title{
The internet, a new area of dispute by the memory of the military dictatorship in Brazil
}

\begin{abstract}
The post-modernity period, which at first sight seemed to have relegated History to an irrelevant level, ended up by triggering a movement for memory evaluation. In Brazil, the 3rd Human Rights Plan (2010) transformed that trend into public politics by adapting the "Right to Memory and Truth" as one of its aims. That governmental approach, combined with a new communication paradigm, instigated the dispute around the construction of the collective memory during the period of Military Dictatorship in Brazil, turning the internet into an important place for this debate. The importance of the subject derives from the comprehension of memory acting as a factor of cohesion and affirmation of values. Memory may have influence on social behavior and may interfere in the way power is exercised. Thus, by analysing two representative sights, we intend to rescue the values around which each group seeks to support its own 'truth' to interfere in the way national memory is built.
\end{abstract}

Keywords: Memory. Communication. Power. Military Dictatorship-Brazil. Brazil-History (Military Period). 


\section{Introdução}

No contexto da pós-modernidade, a sociedade passou a ser cada vez mais 'programada' pela difusão de mensagens via tecnologia eletrônica de comunicação de massa, que vem provocando intensas transformações na vida social (SANTOS, 2006). Vivemos num ambiente cada vez mais dominado pela informação e pela comunicação midiática - com destaque para as redes interativas -, que se apresenta como expressão de nossa cultura (CASTELLS, 2009) e como principal responsável pelos estímulos e pela fixação das mensagens de conteúdo simbólico no meio social, gerando uma sociabilidade mediada (THOMPSON, 1995). Santos (2006) enfatiza que, nesse universo, saturado de informações e signos, a sociedade caminha para forte individualismo, para o consumismo excessivo e hedonista, para o mundo da aparência, do simulacro. É a sociedade do espetáculo descrita por Debord (1997).

Na sociedade informacional, para utilizarmos a expressão de Castells (1999), o sujeito parece vivenciar um sentimento de esvaziamento; tudo é plural, inacabado e indefinido. O homem pós-moderno vem perdendo a perspectiva da continuidade, vivendo um presente instantâneo e sem nenhum referencial de passado (SANTOS, 2006). Parece consenso ter a pós-modernidade transformado nossa percepção do tempo. A capacidade técnica de transmissão simultânea de numerosos eventos impôs às sociedades maior dificuldade em absorver esses acontecimentos enquanto parte de sua própria História; desse modo, passamos a viver uma situação de desnorteamento, uma espécie de crise de sentido. Nesse ambiente, a História parece seriamente ameaçada, relegada ao campo da irrelevância, o que coloca a todos sob o "risco de uma espécie de amnésia coletiva voluntária" (CARDOSO, 2005, p.16). Trata-se de uma situação preocupante, uma vez que a memória individual, componente que garante nossa inserção social e nossas convicções, deriva da percepção de que pertencemos a um grupo e compartilhamos uma História, garantindo nossa identidade coletiva; portanto, recuperar e transmitir o passado histórico para sucessivas gerações torna-se um imperativo das sociedades.

Dada a necessidade de criar ou fortalecer este sentido social, nascem movimentos que não recusam o novo, mas o esquecimento (LA TAILLE, 2009), o que nos remete ao 
divergentes. A relevância do tema deriva da compreensão da memória enquanto importante fator de coesão, indispensável para a afirmação de reivindicações, direitos e valores - em última análise -, para o exercício do poder.

Considerando que, em tempos de sociedade em rede (CASTELLS, 1999) não há espaço para as relações de poder fora do campo da comunicação - cuja importância foi potencializada pela difusão dos processos de digitalização/transmissão de conteúdos diversos por sistemas multimídia -, podemos inferir que esse universo comunicativo se torna um locus privilegiado da disputa em questão. Partindo dessas premissas, interessanos, neste artigo, analisar o conteúdo divulgado em sites específicos e representativos desse embate pela memória da Ditadura Militar no Brasil, buscando resgatar os valores que sustentam esses discursos, por seu poder de interferência na posição política dos cidadãos, algo significativo para o exercício do poder num Estado democrático.

\section{Memória, Poder e Comunicação: apontamentos teóricos}

Para Halbwachs (2006), devemos atribuir a memória a uma entidade coletiva: a sociedade. Uma vez que o indivíduo está nela inserido, ele se lembra "enquanto membro de um grupo" (RICOEUR, 2007, p. 131), havendo mútua interferência entre memória individual e coletiva. Importante destacar que essas memórias coletivas, originárias da percepção interna de um grupo, estão comprometidas com a salvaguarda de acontecimentos e de interpretações do passado (POLLAK, 1989) e carregam uma apreciação moral ou juízo de valor (CARDOSO, 2005). Portanto, ainda que sua pretensão seja a verdade (RICOEUR, 2007), a memória pressupõe seleção simultânea dos fatos que serão lembrados ou esquecidos de acordo com nossas convicções; uma interação entre conservação e apagamento vinculada a eventos de identidade (TODOROV, 2000@), ou de constrangimento na história de determinado povo (LE GOFF, 2003). 
Todorov (2000®) afirma que essa seleção, a priori, não representa um problema, visto ser uma dinâmica intrínseca da atividade mnemômica. Para o autor, as questões fundamentais dizem respeito à percepção de mundo e aos usos que atores do processo de construção e fixação da memória coletiva pretendem imprimir ao passado recuperado - uso que pode ser colocado a serviço de um grupo social, de uma ideologia ou de um regime político. Logo, quando o indivíduo passa da memória para a História, aventurandose na recuperação e no registro histórico, está interferindo na visão que os indivíduos terão da trajetória histórica da qual fazem parte, e isso implica valores que nortearão as ações e as relações sociais.

Le Goff (2003, p.422) alerta para o fato de que:

tornar-se senhores da memória e do esquecimento é uma das grandes preocupações das classes, dos grupos, dos indivíduos que dominaram e dominam as sociedades históricas. Os esquecimentos e os silêncios da história são reveladores destes mecanismos de manipulação da memória coletiva.

Inferimos, portanto, que memória é poder. Recorrendo a Foucault (1988), podemos afirmar que a reconstrução da memória se revela estratégia fundamental para o exercício do poder, pois constrói representações intencionais. A ideologia que permeia a recuperação da memória é determinante no que tange à sua manipulação, pois pode atuar distorcendo a realidade, legitimando a ordem político-social e garantindo-lhe credibilidade (RICOEUR, 2007). Para a discussão aqui proposta, é importante destacar que a memória coletiva - construída segundo conveniências de indivíduos ou grupos - "se converte em um discurso, em algo comunicado" (ARÓSTEGUI, 2006, p. 290), sendo determinante dispor de meios eficientes para difundi-lo. Na atualidade, impõe-se a discussão acerca da difusão pelas redes, uma estrutura de comunicação distribuída (GALLOWAY, 2004) que domina o cenário mundial.

Nessa perspectiva, devemos considerar que a comunicação é um fenômeno social de grande relevância, que estabelece relações entre indivíduos socialmente engajados, com objetivos definidos e em contextos históricos específicos. Na sociedade pósmoderna, momento em que o paradigma da comunicação humana vem se alterando pela 
em rede (THOMPSON, 1995), esse ambiente informacional torna-se um campo privilegiado de construção e difusão dos valores que moldam a cultura e os comportamentos. Portanto, torna-se um espaço de poder. Para o debate aqui proposto, interessa-nos particularmente a internet como campo virtual saturado de tensões e expressão das lutas e conflitos que se processam em diferentes registros.

Em virtude do alcance, da abrangência e da alta capacidade interativa dessa nova forma de comunicação de massa, que Castells (2009, p. 55) chama de mass selfcommunication, a presença dos atores políticos na internet garante maior visibilidade e torna a rede decisiva no jogo de poder presente nas relações sociais. Para Castells, a importância fulcral da ação comunicativa em rede nas sociedades democráticas contemporâneas está exatamente em características tais como espaços múltiplos e autônomos, que podem atuar na legitimação do poder constituído ou na organização de movimentos de resistência a governos ou a projetos políticos específicos.

Desse modo, as redes se têm definido também como espaços de confronto, obrigando atores políticos em disputa a criar conexões e redes de compartilhamento de informações e ideias, visando a influenciar a opinião pública, garantir apoio ou modificar decisões políticas. Essa situação, no que se refere à memória sobre o período ditatorial brasileiro, foi deflagrada pela política de Direitos Humanos do governo federal a partir de 2009, fato que nos obriga a uma breve caracterização para avançar na análise.

\section{Da Distensão Política ao $3^{\circ}$ Plano Nacional de Direitos Humanos (PNDH-3)}

Passados dez anos do movimento responsável pela implantação da ditadura no país, seguido de um período de recrudescimento e crescente arbitrariedade conhecido como 'anos de chumbo' (1969-1973), chegava ao poder o general Ernesto Geisel. Sob seu governo, o Brasil iniciou um longo processo de abertura - 'lenta, gradual e segura'-, 

não contemplou a proposta de uma anistia 'ampla, geral e irrestrita' como defendia a Campanha Nacional da Anistia. Foram excluídos indivíduos acusados de participarem de luta armada contra o governo; em contrapartida, o texto, um tanto vago, garantiu a extensão da anistia aos possíveis colaboradores do Estado em suas ações de combate à subversão, nas quais o desrespeito aos direitos humanos, com destaque para a tortura, era instrumento recorrente. Essa lei tornou possível o retorno de exilados e a libertação de presos políticos que, aproveitando-se de um ambiente cada vez mais livre, iniciaram, na década de 1980, uma intensa produção editorial de caráter memorialista².

Estas primeiras publicações enfatizavam questões bastante sensíveis, com narrativas de grande apelo emocional, ligadas a experiências dramáticas de sofrimento e humilhações até então sufocadas. Tais obras tiveram forte impacto junto à opinião pública, configurando importante fonte documental para estudiosos que se dedicam ao trabalho de construção da História Nacional.

Para os militares, essa produção significou o esforço da esquerda "por vencer, na batalha das letras, aquilo que perdeu no embate das armas" (MARTINS FILHO, 2002, p. 2). Neste sentido, tendo em vista o peso e o grau de aceitação das narrações dos opositores, os militares, inquietos e, supomos, sentindo-se atacados, reagem. A partir de 1985, estando o País já sob um governo civil, surgem obras, também de caráter memorialista, escritas a partir de seu olhar. Destacam-se os depoimentos de oficiais que estiveram à frente do controle político do país no período ditatorial ${ }^{3}$.

Percebe-se, portanto, que, ultrapassada a esfera clássica de luta pelo poder - o Estado -, a disputa que caracterizou a ditadura se transformou em uma luta política pela

\footnotetext{
${ }^{1}$ Lei $\mathrm{n}^{\circ} 6.683$ de 28 de agosto de 1979. Texto integral disponível em: http://www.planalto.gov.br/ccivil_03/leis/L6683.htm Acessado em 26 set. 2013.

${ }^{2}$ Sobre o tema, ver MARTINS FILHO, J. R. 2002.

${ }^{3}$ A título de exemplos, destacamos: D’ARAÚJO, M. C; CASTRO, C. Ernesto Geisel. RJ: FGV, 1997; USTRA, C. A. B. Rompendo o silêncio. Oban/Doi-Codi. Brasília: Editerra Editorial, 1987.
} 

nova orientação em relação aos direitos humanos, tema que ganhou proeminência com a promulgação da Constituição de 1988. Traduzindo-se num compromisso legal do Estado, a nova Carta significou expressivo avanço, incluindo vasta e pormenorizada lista de direitos que deveriam ser garantidos pelo poder público. De fato, somente a partir do governo FHC, o País conseguiu avançar, com o lançamento do Programa Nacional de Direitos Humanos - $\left(\mathrm{PNDH}^{4} / 1996\right.$ e II $\left.\mathrm{PNDH}^{5} / 2002\right)$-, com o objetivo de ampliar e consolidar as ações até então desenvolvidas.

Desse modo, o PNDH-36 (Decreto 7.037/2009, atualizado pelo Decreto 7.177/2010), aprovado no governo Lula, deve ser compreendido como a continuidade de um compromisso assumido com a redemocratização, que transformou a promoção e a realização dos direitos humanos em um ponto relevante da agenda estatal, conforme orientava a Conferência Mundial de Direitos Humanos (ONU, Viena, 1993). Em última análise, considerando a relativa estabilidade política vivenciada pelo País nas últimas décadas, devemos reconhecer que essa agenda foi desenhada, enquanto política pública, pela evolução histórica do País e não por interesses particulares (SOUZA, 2006).

Tendo em vista a necessidade de se enfrentar um problema ainda bastante sério no Brasil, o cerne do projeto está na construção de um sentimento de coesão em torno da importância da defesa dos direitos humanos a partir da consciência coletiva. Segundo o então presidente, o objetivo era agregar demandas crescentes da sociedade, como uma “verdadeira política de Estado" (BRASIL, 2010, p.11), contemplando vários setores, numa perspectiva transversal e interministerial.

\footnotetext{
${ }^{4}$ Nesse momento, foram priorizados os direitos civis fundamentais, voltados a garantir a preservação da vida http://www.planalto.gov.br/ccivil_03/decreto/d1904.htm. Acessado em 02.03.2012.

${ }^{5}$ Partindo da premissa de que os direitos humanos englobam direitos indivisíveis e interdependentes, serão incluídos direitos econômicos, sociais e culturais. http://portal.mj.gov.br/sedh/pndh/pndhII/Texto\%2olntegral\%20PNDH\%2oll. Acessado em: 2 mar.2012.

${ }^{6}$ http://www.sedh.gov.br/pndh/pndh3.pdf. Acessado em: 2 mar. 2012.
} 
O programa foi organizado em torno de seis eixos norteadores. Destacamos, entre eles, o eixo “Direito à Memória e à Verdade", que associa cidadania, identidade e memória histórica coletiva e destaca a urgência de resgatar fatos ocorridos na história recente do País, particularmente pós 1964, visando a promover, finalmente, a “reconciliação nacional” (BRASIL, 2010, p. 173).

Uma iniciativa anterior havia deixado o trabalho de organizar e divulgar as informações contidas nos documentos de arquivos - até então sob a tutela da Agência Brasileira de Inteligência (ABIN) - sob responsabilidade do Arquivo Nacional. Como resultado, em 2007 foi lançado o livro-relatório Direito à Memória e à Verdade, relatando a história de vítimas da Ditadura Militar.

Em 2009, pretendendo ampliar a circulação das informações, o governo lançou o Centro de Referência das Lutas Políticas no Brasil (1964-1985): Memórias Reveladas', site responsável por interligar os acervos digitais organizados pelo Arquivo Nacional. O portal também passou a ser um espaço de interlocução entre Estado e cidadão, na busca por informações que permitiriam esclarecer inúmeros casos de morte e desaparecimento de opositores, bem como de fomento à pesquisa e ao debate.

Não podemos ignorar que, segundo estudiosos do tema, a essência das políticas públicas é o "embate em torno de ideias e interesses" (SOUZA, 2006, p. 25), o que explica o fato de que todas essas iniciativas tenham reacendido, no meio jurídico e social, o debate acerca da interpretação da Lei da Anistia, em especial no tocante à prescrição ou imprescritibilidade dos crimes de tortura cometidos durante a ditadura ${ }^{8}$, o que naturalmente incitou reações indignadas entre os militares, alimentando ainda mais a disputa em torno da recuperação histórica do período.

\footnotetext{
${ }^{7}$ http://www.memoriasreveladas.arquivonacional.gov.br/cgi/cgilua.exe/sys/start.htm?sid=15. Acessado em: 27 mar. 2012.

${ }^{8}$ Em 1995, foi aprovada a lei 9.140, que 'reconheceu a responsabilidade do Estado brasileiro pelas mortes de opositores do regime de 1964' (PNDH-3, 2010, p. 170). Desde então, a criação da Comissão Especial sobre Mortos e Desaparecidos (CEMDP), em 1995, e da Comissão da Anistia, em 2001, levaram à abertura de diversas ações judiciais de reparação, pagamentos de indenizações, busca por restos mortais e concessão de anistia. Além disso, foi criada a Comissão da Verdade (2011), cujo papel seria contribuir com os órgãos oficiais do Estado no 'esclarecimento público das violações dos Direitos Humanos por agentes do Estado na repressão aos opositores' (PNDH-3, 2010, p.13), inclusive caracterizando estruturas utilizadas, ramificações e procedimentos.
} 
Desse modo, não tardou a surgir o contraponto a essa política por parte de militares e simpatizantes do extinto governo militar. Em consonância com nossa proposta, destacamos o lançamento do site A Verdade Sufocada ${ }^{9}$, cujo objetivo, segundo seus proponentes, é contar a outra (e verdadeira) versão dos fatos, uma verdade que, segundo eles, a chamada esquerda gostaria de ocultar.

Resgatar esse embate e os valores que perpassam o discurso apresentado não apenas contribuirá para a melhor compreensão do período em questão, mas também será revelador do potencial comunicativo e político das redes, que não poderá ser negligenciado nas sociedades do século XXI.

\section{O embate pela memória no ambiente informacional de redes}

Iniciaremos com a análise do site oficial surgido como parte das ações do PNDH-3, Memórias Reveladas ${ }^{10}$. Cabe ressaltar que, além de ser um meio de comunicação, é um site oficial do Estado, o que o torna duplamente poderoso.

Trata-se de um ambiente virtual bastante atraente e dinâmico, cuja pretensão memorialista já fica clara na apresentação de seu perfil pela então ministra chefe da Casa Civil (2010), Erenice Guerra: "para que não se esqueça, para que nunca mais aconteça”.

Reúne farta documentação: são textos, vídeos, mapas, charges, exposições de fotos e uma linha do tempo ilustrada. Além disso, disponibiliza para download uma ampla produção editorial, com livros e revistas cujo conteúdo foi desenvolvido com a colaboração de profissionais e intelectuais de diferentes áreas, procurando, nitidamente, reforçar sua qualidade e credibilidade.

Analisando parte expressiva desse material, logo se percebe a tônica do discurso: o golpe de 1964 usurpou as liberdades e desrespeitou os direitos humanos mais elementares, tendo derrubado um governo legítimo e que tinha amplo apoio da

\footnotetext{
${ }^{9} \mathrm{http} / / /$ www.averdadesufocada.com/index.php?option=com_content\&task=category\&sectionid=4\&id=50\&l temid=98. Acessado em: 5 abr. 2012.

${ }^{10} \mathrm{http}: / /$ www.memoriasreveladas.arquivonacional.gov.br/cgi/cgilua.exe/sys/start.htm?sid=15. Acessado em: 27 mar. 2012
} 
está na violência perpetrada contra os grupos que resistiram, sobretudo depois do $\mathrm{Al}-5$ (1968), destacando particularmente a tortura como parte da dinâmica de repressão do Estado, que teria resultado em feridas físicas e psicológicas ainda não cicatrizadas.

Segundo os documentos, essa resistência incluiu pessoas comuns, desarmadas e indefesas, que buscavam construir um novo paradigma político-econômico-social; Brito (2010, p. 28) afirma tratar-se de 'uma geração que ansiava reformar a velha e conservadora sociedade brasileira' em luta contra um poder opressor e com elevada capacidade de repressão. Os fatos ocorridos no Brasil são apresentados como parte de um contexto histórico mundial mais amplo, cujo marco é 1968, ano em que explodem inúmeros movimentos de rebeldia em defesa da liberdade, em diferentes países.

Seguindo a mesma linha, as referências à guerrilha no Brasil apresentam-na como ações altruístas de indivíduos comprometidos com a justiça social e identificados com o ideal comunista; uma luta armada em nome da democracia, portanto, libertadora, que teria utilizado de violência em nome de uma causa maior e justa, o que nos remete ao legítimo direito à resistência (AGAMBEN, 2004) contra uma ordem ilegítima e opressiva.

Em relação à abertura, destacam-se o retorno das mobilizações populares em nome da redemocratização e, nesse processo, a assinatura da Lei da Anistia. Enquanto parte de um programa voltado aos direitos humanos, não surpreende o fato de que grande parte do material disponível esteja focada nas recentes críticas ao conteúdo e/ou à interpretação da lei.

Brito (2010, p. 30) reconhece que ela teria contribuído para uma transição pacífica; entretanto, enfatiza que "não pode ela ser utilizada para impor a amnésia a toda uma sociedade" como pretendiam os militares, razão por que se enfatiza a argumentação em dois aspectos: a necessidade de identificação e de punição dos agentes da repressão (responsáveis pelas mortes e desaparecimentos) e a importância do trabalho de 'revelação' da memória, essencial no processo de consolidação democrática. 
No que tange ao primeiro aspecto, Miranda (2009, p. 33), lembrando o caso argentino", afirma que "anistia não é perdão, é um ato reparatório que não pode se estender aos que agiam em nome de um estado inconstitucional"; segundo o autor, não se trata de revanche, mas de justiça. Procurando reforçar essa posição, o site traz depoimentos e fotos que destacam a luta dos familiares, os abusos cometidos contra crianças e a experiência de jovens cujas vidas foram transformadas após terem presenciado atos de violência nas celas em que estiveram, muitas vezes, presos com seus pais.

Sem dúvida, o tom emotivo e indignado das narrativas reforça o caráter de denúncia, com a clara pretensão de sensibilizar o leitor, de mexer com suas emoções de modo a interferir no comportamento social e influenciar sua postura política. Uma vez que, segundo Castells (2009, p.145), “o cérebro político é um cérebro emocional”, essa estratégia poderia garantir apoio à política pública do Estado e, em última análise, ao partido do governo.

Frente a fatos tão dolorosos, a negação do esquecimento se vincula à defesa da liberdade e da justiça, a atitudes de responsabilidade e comprometimento com os valores fundamentais da vida humana, da cidadania e da paz; na opinião de juristas, é parte importante da Justiça de Transição ${ }^{12}$. Disso decorre a importância de se garantir o acesso universal e democrático à informação, apresentada como um "bem público, um valor"13, justificando e legitimando a decisão de abertura dos arquivos do Serviço Nacional de Informação, órgão fundamental do aparato repressivo da ditadura.

Claro está que a revelação desses documentos, proposta considerada 'controvertida', tornou-se dependente da vontade política - uma vez que são notórios os interesses comprometidos com sua ocultação. Trata-se de uma luta política que o

\footnotetext{
${ }^{11} \mathrm{Na}$ Argentina, tomando como base o direito internacional, foram julgados e punidos os elementos identificados com a tortura.

12 Justiça de transição refere-se a um conjunto de medidas judiciais estabelecidas durante e/ou após um contexto de transição de regimes autoritários para regimes democráticos, ou em momentos pós-guerra, pós-violência ou pós-conflito. Estas medidas têm como objetivo o estabelecimento de reparações e/ou reconciliações que possam contribuir para a democracia e a paz (SANTOS, 2010, p. 125).

${ }^{13}$ Segundo José Genoíno, em entrevista disponível no site http://www.memoriasreveladas.arquivonacional.gov.br/cgi/cgilua.exe/sys/start.htm?sid=15.
} 

Nitidamente, é uma luta pelo poder.

Segundo Barbosa (2008, p. 28-29), a preservação da memória histórica fundada na verdade, além de interferir nas relações humanas, orientar e transformar os valores e as ações sociais em defesa da liberdade, é "um ato de resistência", uma vez que as ditaduras, em geral, se utilizam da estratégia do esquecimento e do silêncio para não "ajustar contas com o passado", omitindo fatos históricos e deixando as futuras gerações na ignorância. Nessa mesma linha, Schilling (2010), adotando uma perspectiva foucaultiana, aponta a memória como arma libertadora, uma vez que o conhecimento empodera e abre caminho para a resistência.

Genro e Abrão (2010, p. 19-20) destacam que "a recuperação da memória não se faz (...) sem o confronto de valores"; portanto, um dos objetivos implícitos desse resgate é o de combater "uma memória cristalizada nos valores da dominação autoritária", a partir de um debate democrático que teria sido o norte do PNDH-3.

Apesar dessa inflexão discursiva, seus defensores procuram ressaltar o potencial pacificador da verdade; ao contrário do que dizem os críticos, os autores afirmam que ela não alimentará o ódio e o revanchismo, mas garantirá a verdadeira reconciliação nacional.

Em suma, destacando o caráter coletivo de nossa experiência ditatorial, o programa enfatiza a necessidade de uma expiação também coletiva dos acontecimentos, dos sofrimentos e das violências cometidas e sofridas, de modo a fortalecer os valores positivos que orientarão o comportamento político e social dos cidadãos no presente.

Em resposta a essa abordagem, temos o projeto $A$ Verdade Sufocada ${ }^{14}$, cuja origem é o livro do coronel Carlos Alberto Brilhante Ustra: A verdade sufocada. A história que a esquerda não quer que o Brasil conheça ( $7^{\text {a }}$ edição. Brasília: Editora Ser, 2011) $)^{15}$. Interessante

\footnotetext{
${ }^{14} \mathrm{http}$ //www.averdadesufocada.com/index.php?option=com_content\&task=category\&sectionid=4\&id=50\& Itemid=98. Acessado em: 5 abr. 2012.

${ }^{15}$ Pareceu-nos interessante relatar que, segundo a editoria do site, o livro enfrentou grandes dificuldades para ser editado e comercializado em função da recusa por parte de inúmeras livrarias; acabou por ser
} 

do País. Verifica-se, portanto, uma reação explícita ao projeto Memórias Reveladas. Tratase de um ambiente bem-organizado, reunindo vasto material e promovendo intenso debate em torno da temática. A quantidade de acessos é bastante expressiva, o que denota o interesse despertado pelo tema, a aceitação desse discurso, além do alcance proporcionado pelas redes.

São depoimentos, vídeos, textos e citações jornalísticas, links com blogs e espaços para comentários de visitantes que, salvo raras exceções, vêm em apoio à iniciativa do coronel Ustra, apontado como um homem de coragem moral e intelectual, disposto a contar a versão de quem venceu a guerra contra um inimigo interno rancoroso e mentiroso. Em geral, o debate converge para os temas mais polêmicos, projetados pelo lançamento do PNDH-3: a definição e as razões de 1964, as estratégias e os desdobramentos da repressão imposta pelo regime militar, a luta armada empreendida pelos opositores e a Lei da Anistia.

Numa breve recuperação de seu conteúdo, podemos apontar com bastante segurança a opinião (quase) unânime em torno do caráter contra-revolucionário (e não golpista) do movimento militar de 1964. Os militares, sustentados em amplo apoio da sociedade, teriam agido em defesa da segurança nacional, das liberdades democráticas, da soberania e da paz social contra o comunismo internacional, subversivo e ditatorial, que se infiltrava, provocando mortes de inocentes e levando o País ao caos, ao desgoverno e à iminência de uma guerra civil.

Procurando compreender o discurso à luz da teoria, recorremos aos estudos de Agamben (2004, p. 29), que nos remete ao conceito de “democracia protegida". Trata-se da justificativa clássica do chamado "estado de exceção", verdadeira "esquizofrenia ideológica", segundo O’Donnell e Schmitter (1988a, p. 35): o inevitável recrudescimento do regime em defesa de um suposto ideal democrático, cada vez mais ameaçado, uma vez

financiado pelo próprio autor e já vendeu milhares de cópias, apesar desse suposto patrulhamento ideológico, o que seria bastante significativo. 
de apresentar-se como um dado objetivo, implica claramente um juízo subjetivo" (AGAMBEN, 2004@, p. 46), portanto derivado de valores.

Seguindo essa mesma linha, uma vez no poder, os militares teriam enfrentado, com força e determinação, a violenta e covarde reação dos opositores, segundo eles, terroristas financiados por cubanos e soviéticos que, de armas em punho, procuravam aliciar jovens para a luta armada. Segundo os responsáveis pelo site, essas ações, verdadeiros crimes contra a pátria, foram sufocadas por uma bem-elaborada e eficiente estrutura, necessária para neutralizar o perigo; uma situação que teria levado os militares a cometerem alguns “excessos" ${ }^{16}$.

As Forças Armadas são apresentadas como uma instituição da mais alta confiabilidade do povo brasileiro, formada por homens corajosos, legalistas e altruístas, cuja obrigação moral era servir à Pátria e garantir a estabilidade jurídica acima de qualquer interesse pessoal. Considerando que o Exército é uma das mais antigas instituições burocráticas do Estado brasileiro, a que se implantou em 1964 seria uma administração pautada no "simples conceito de dever" (WEBER, 2000, p.147).

Dessa percepção decorre, segundo a editoria e seus colaboradores, a urgência de se fazer um chamado aos brasileiros honestos, um alerta à juventude acerca da importância de se buscar a verdade, derrubando o mito de que as Forças Armadas lutaram com seus tanques contra inocentes estudantes armados de pedras.

Rejeitando a denominação "memórias reveladas", acusam o governo de impedir o acesso à documentação e criticam o tom ameno e superficial que o site utiliza ao falar da resistência, alçando os envolvidos à categoria de heróis nacionais. Trata-se, na sua perspectiva, de uma "verdade sufocada" pela esquerda, que se refugiou nas universidades e no movimento editorial de onde ataca, tentando garantir sua hegemonia

\footnotetext{
${ }^{16}$ Interessante notar que, em geral, os militares negam que houvesse práticas de tortura e afirmam que foram hábeis em controlar a perigosa situação, causando um pequeno número de mortos em comparação com os demais países da América Latina.
} 
cultural a partir da manipulação da verdade histórica; um trabalho de perigosa doutrinação da juventude que precisa ser desmascarado.

Neste sentido, a Lei da Anistia - cujo propósito, segundo eles, seria o de pacificar o País, deixando para trás os conflitos e as divergências em nome da construção de um país livre - estaria sendo alvo de um projeto revanchista, levado a efeito por indivíduos que ascenderam ao poder com a posse do ex-presidente Lula, cuja autoridade não contestam em função da reconhecida e respeitada legitimidade político-eleitoral. Nesse caso, entendem que a agenda política teria sido definida, claramente, pela mudança do grupo que governa, respondendo ao interesse pessoal de participantes dos quadros governamentais e não da coletividade (SOUZA, 2006).

Cercados de bons formadores de opinião e contando com o apoio de setores da mídia, os revanchistas estariam utilizando novas armas na batalha pelo poder, desmoralizando, de modo contundente, o regime militar e as Forças Armadas e promovendo a execração pública de indivíduos que morreram em defesa da pessoa, da família, da vida, da religião, da fraternidade e da honestidade.

Estes indivíduos, comprometidos com uma verdadeira "cruzada moral” (CASTELLS, 2009, p. 244) discurso característico das vertentes políticas mais conservadoras em diferentes países - profetizam que essa completa inversão de valores representa uma ameaça latente à liberdade, à propriedade, ao Estado e à Democracia, conduzindo a Nação brasileira à desordem e à instabilidade jurídica.

Partindo dessa breve caracterização de ambos os sites, podemos perceber que o alvo privilegiado, nos dois casos, é a juventude, o que se explica pelo fato de ser a internet sua fonte preferencial de informações. Valendo-se da autonomia para a postagem de conteúdo, ambos criam mensagens políticas que destacam vilões e vítimas, sempre enfatizando aspectos negativos e denunciando ações ilícitas ou condenáveis de seu opositor, ao mesmo tempo em que cultivam uma autoimagem de liderança positiva; uma estratégia que talvez nos permita relacionar ao que Castells (2009, p.193) chama de "política do escândalo". 
Sem dúvidas, nesse embate pela memória, a rede se mostra um meio de difusão altamente eficiente para grupos objetivamente interessados em interferir na construção das práticas sociais que reivindicam o reconhecimento da 'sua' verdade, justificando suas ações pela defesa de valores e crenças que, com certa margem de certeza, são compartilhados pelo público em geral. Estudos apresentados por Castells (2009) apontam que as pessoas procuram informações que reforcem o seu posicionamento pessoal frente a questões político-ideológicas, o que explicaria, por exemplo, as incontáveis manifestações de apoio à iniciativa do cel. Ustra.

Além disso, o apelo emocional é visível em ambos os sites, o que se explica, segundo Castells (2009), pelo peso expressivo que as emoções, sobretudo as negativas, têm no posicionamento e na tomada de decisões políticas dos indivíduos; trata-se de uma abordagem capaz de garantir a absorção dos valores constitutivos do discurso. Dessa forma, podemos compreender os fatos destacados pelos sites que despertam solidariedade, medo, indignação e até raiva; assim, estariam despertando sentimentos e emoções que remetem o leitor às experiências de um passado que se pretende resguardar.

Não obstante, devemos considerar que a pura e simples exposição desse material não garante a adesão a um ponto de vista específico. A interpretação dessas mensagens também ocorre de forma contextualizada, influenciada pelas expectativas pessoais e/ou sociais que serão decisivas na construção de sentido e na incorporação (ou não) do conteúdo transmitido, dinâmica que impede que os indivíduos se transformem em meros receptores acríticos e passivos de manipulação ideológica, garantindo certa autonomia para organizar e decidir comportamentos frente a qualquer mensagem (CASTELLS, 2009; THOMPSON, 1995).

Por fim, parece-nos importante ter em mente que, em que pesem as inúmeras tentativas de manipulação da memória, não podemos ignorar, conforme afirma Cardoso (2005, p. 20), que "o passado está dotado de firme consistência e resiste às manobras de distorção e livre reconstrução". Portanto, sabendo que "nas batalhas de memória, o jogo nunca está definitivamente disputado" (REIS, 2004, p. 30), o desafio da verdade nos 
obriga a problematizar a memória, questionando, de acordo com Todorov (2000®), os resultados dos atos que se pretendem fundados sobre ela.

\section{Considerações Finais}

O advento da pós-modernidade transformou em muitos aspectos a experiência humana tanto em suas dimensões físicas como imateriais. É inegável, portanto, que a construção dos significados simbólicos que asseguram a homens e mulheres sua percepção enquanto ser social está muito longe de se tornar desprezível. Como nos lembra Huyssen:

um dos fenômenos culturais e políticos mais surpreendentes dos anos recentes é a emergência da memória como uma das preocupações culturais e políticas centrais das sociedades ocidentais. Esse fenômeno caracteriza uma volta ao passado que contrasta totalmente com o privilégio dado ao futuro que tanto caracterizou as primeiras décadas da modernidade do século XX (HUYSSEN, 2004, p. 9).

No Brasil atual, vemos a memória sendo contemplada pela política pública do governo federal, que a entende como "direito do cidadão, portanto como ação de todos os sujeitos sociais e não como uma produção oficial da história" (CHAUÍ, 2006, p. 125); sem dúvida, uma percepção indissociável do processo de consolidação democrática vivido pelo País nas últimas décadas.

Sob o impacto das novas tecnologias da informação, essa questão chega à internet, que se torna um terreno fértil para os dissensos inevitáveis entre os sujeitos sociais e os atores políticos mais diretamente interessados em participar da escrita da História Nacional e/ou com ela contribuir. Desse modo, estes indivíduos se sentem obrigados a atuar na rede, sob o risco do perder sua capacidade de influenciar a opinião pública.

Cabe ressaltar que a própria estrutura de comunicação em rede dificulta a construção de um discurso hegemônico (CASTELLS, 2009), a exemplo do que vem ocorrendo com a construção da memória histórica recente do Brasil, alvo de divergências aparentemente inconciliáveis. Apesar disso, e mesmo considerando que, com frequência, 
Resgatar essa memória é fundamental para o aprofundamento da democracia; contribuirá para mudar a lógica do poder que hoje temos, construindo uma nova relação entre Estado e Sociedade (SANTOS, 1999).

Logo, ainda que em meio a tensões e conflitos, devemos considerar, sim, o potencial democratizante das novas tecnologias da informação que, fomentando o debate crítico a respeito de diferentes temáticas, promove a mobilização e a cidadania participativas, contribuindo de maneira muito positiva na contestação frente à arbitrariedade, ao autoritarismo e à intolerância.

Além disso, considerando as reflexões propostas por Penteado, Santos e Araujo (2011), as tecnologias da informação se têm mostrado um caminho eficiente no sentido de permitir a interferência na definição das políticas públicas - a exemplo do que ocorre no Brasil em relação à memória -, para que sejam mais condizentes com as demandas e os valores dos cidadãos, bem como para sua avaliação, o que pode fortalecer o poder representativo, um tanto desacreditado em nossos dias. Trata-se de criar uma nova cultura política, em que a democracia representativa e a participativa não sejam consideradas incompatíveis.

Nessa perspectiva, parece-nos certo que resgatar esse embate na atualidade - e, mais do que isso, dele participar - poderá enriquecer nossa compreensão do Brasil que emergiu após a ascensão do governo civil, pois “o denominador comum de todas essas memórias, mas também as tensões entre elas, intervêm na definição do consenso social e dos conflitos num determinado momento conjuntural" (POLLAK, 1989, p. 11).

Recorrendo novamente a Todorov (2000®), consideramos importante frisar que devemos recuperar o passado para que dele se extraia uma lição; desse modo, conseguiremos transformá-lo em um princípio de ação para o presente, tornando-o potencialmente libertador, voltado para a justiça e para o combate aos males que se produzem na atualidade. 


\section{Referências}

AGAMBEN, Giorgio. Estado de exceção. São Paulo: Boitempo, 2004.

ARÓSTEGUI, Julio. A pesquisa histórica: teoria e método. Tradução Andréa Dore; revisão técnica José Jobson de Andrade Arruda. Bauru, SP: Edusc, 2006.

BARBOSA, Marco Antônio. Rodrigues. Direito à memória e à verdade. Revista Direitos Humanos. Brasília. DF: Secretaria Especial dos Direitos Humanos da Presidência da República do Brasil, n. 1, 2008. p. 26-33.

BRASIL. Presidência da República. Secretaria Especial dos Direitos Humanos. Direito à memória e à verdade: histórias de meninas e meninos marcados pela ditadura. Brasília, 2009.

BRASIL Presidência da República. Secretaria de Direitos Humanos. Programa Nacional de Direitos Humanos. (PNDH-3). Revisto e atualizado - Brasília: SDH/PR, 2010. Disponível em <http://www.sedh.gov.br/pndh/pndh3.pdf> Acessado em: 13 abr. 2012.

BRITO, Cézar. O Direito à memória e à verdade. Revista Direitos Humanos. Brasília. DF: Secretaria Especial dos Direitos Humanos da Presidência da República do Brasil, n. 5, 2010. p. 26-31.

CARDOSO, Ciro Flamarion. Um historiador fala de teoria e metodologia: ensaios. Bauru, SP: Edusc, 2005.

CASTELLS, Manuel. A Sociedade em rede. São Paulo: Paz e Terra, 6. ed., v.1, 1999.

CASTELLS, Manuel. Communication power. New York: Oxford University Press, 2009.

CHAUI, Marilena. Cidadania cultural. São Paulo: Editora Fundação Perseu Abramo, 2006.

DEBORD, Guy. A sociedade do espetáculo. Rio de Janeiro: Contraponto, 1997.

FOUCAULT, Michel. História da sexualidade l: a vontade de saber. Tradução: Maria Thereza da Costa Albuquerque e J. A. G. Albuquerque. RJ: Graal, 1988.

GALLOWAY, Alexander. R. Protocol: how control exists after decentralization. The MIT Press Cambridge, Massachusetts London, England, 2004.

GENRO, Tarso; ABRÃO, Paulo. Memória Histórica, justiça de transição e democracia sem fim. In: SANTOS, Boaventura de S. et al. (Orgs.). Repressão e memória política no contexto ibero-Brasileiro: estudos sobre Brasil, Guatemala, Moçambique, Peru e Portugal. Brasília: Ministério da Justiça, Comissão de Anistia; Portugal: Universidade de Coimbra, Centro de Estudos Sociais, 2010. p. 16-24. 
HALBWACHS, Maurice A memória coletiva. Tradução Beatriz Sidou. São Paulo: Centauro, 2006.

HUYSSEN, Andreas. Seduzidos pela Memória. Rio de Janeiro: Aeroplano, 2004.

LA TAILLE, Yves de. Formação Ética: do tédio ao respeito de si. Porto Alegre: Artemed, 2009.

LE GOFF, Jacques. História e memória. Tradução Bernardo Leitão et al. 5. ed. Campinas, SP: Editora da Unicamp, 2003.

MARTINS FILHO, João Roberto A guerra da memória: a ditadura militar nos depoimentos de militantes e militares. São Paulo: UFSCar, 2002. Disponível em:

<http://lasa.international.pitt.edu/Lasa2003/FilhoJoaoRobertoMartins.pdf>. Acessado em: 13 abr. 2012

MIRANDA, Nilmário. Aos 30 anos, anistia ainda é um processo inconcluso. Revista Direitos Humanos. Brasília. DF: Secretaria Especial dos Direitos Humanos da Presidência da República do Brasil, n. 2, 2009. p. 31-34.

MOURA, Gyl Giffony Araújo. Políticas públicas e construções da memória social: um estudo a partir do Centro Cultural Bom Jardim, em Fortaleza, Ceará. In: Anais... do XI Congresso Luso-Afro-Brasileiro de Ciências Sociais. Centro de Estudos Afro-Orientais. Salvador: UFBA, 2011. Disponível em:

<http://www.xiconlab.eventos.dype.com.br/resources/anais/3/1308363192_ARQUIVO_Arti go.CONLAB.pdf. Acessado em: 13 abr. 2012>.

O'DONNELL, Guillermo; SCHMITTER, P. Transições do regime autoritário: primeiras conclusões. São Paulo: Vértice, 1988a.

PENTEADO, Claudio Luis de Camargo de; SANTOS, Marcelo Burgos Pimentel dos; ARAÚJO, Rafael Aguiar de Paula. Democracia e Internet: um exercício (ainda) em construção: uma reflexão sobre participação online e políticas públicas. São Paulo: ABCiber, UFABC, 2011. Disponível em: <http://www.ufabcdigital.blog.br/wpcontent/uploads/2011/09/MT_Fluxos-do-poder_Penteado_abciber_2011.pdf $>$. Acessado em: 13 abr. 2012.

PINHEIRO, Paulo Sérgio; MESQUITA NETO, Paulo de. Programa Nacional de Direitos Humanos: avaliação do primeiro ano e perspectivas. Estudos Avançados. v.11, n. 30, 1997. p. 117-134.

POLLAK, Michael. Memória, esquecimento, silêncio. Estudos Históricos, Rio de Janeiro, v. 2, n. 3, 1989. p. 3-15. 
REIS, Daniel Aarão. Ditadura e Sociedade: as reconstruções da memória. In: REIS, D. A.; RIDENTI, Marcelo; MOTTA, Rodrigo Patto Sá. (Orgs.). O golpe e a ditadura militar: quarenta anos depois (1964/2004). Bauru, SP: Edusc, 2004.

RICOEUR, Paul. A memória, a história, o esquecimento. Tradução: Alain François et al. Campinas, SP: Editora da Unicamp, 2007.

SANTOS, Regina Bega dos. Movimentos sociais urbanos. SP: Editora Unesp, 2008.

SANTOS, Cecília MacDowell. Questões de Justiça de Transição: a mobilização dos direitos humanos e a memória da ditadura no Brasil. In: SANTOS, B. de S. et al. (Orgs.). Repressão e Memória Política no Contexto Ibero-Brasileiro: estudos sobre Brasil, Guatemala, Moçambique, Peru Portugal. Brasília: Ministério da Justiça, Comissão de Anistia; Portugal: Universidade de Coimbra, Centro de Estudos Sociais, 2010. p. 124-151.

SANTOS, Boaventura de Sousa. Pela mão de Alice: o social e o político na pósmodernidade. São Paulo: Cortez, 1999.

SANTOS, Jair Ferreira dos. O que é o pós-modernisno. São Paulo: Brasiliense, 2006.

SCHILLING, Flávia. Memória da resistência ou a resistência como construção da memória. In: PADRÓS, Enrique Serra et al. (Orgs.). Ditadura de segurança nacional no Rio Grande do Sul (1964-1985): história e memória. Conexão Repressiva e Operação Condor. 2. ed., revista e ampliada. Porto Alegre: Corag, v. 3, 2010. p. 141-178.

SILVA, Helenice Rodrigues. Rememoração/comemoração: as utilizações sociais da memória. Revista Brasileira de História, v. 22, n 44, 2002. p. 425-438.

SILVA FILHO. José Carlos Moreira. da. Dever de memória e a construção da história viva: a atuação da Comissão de Anistia do Brasil na concretização do direito à memória e à verdade. In PADRÓS, Enrique Serra. et al. (Orgs.). Ditadura de segurança nacional no Rio Grande do Sul (1964-1985): história e memória. O fim da ditadura e o processo de redemocratização. 2. Ed., revista e ampliada. Porto Alegre: Corag, v. 4, 2010. p. 47-92.

SOUZA, Celina. Políticas Públicas: uma revisão da literatura. Sociologias. Porto Alegre, n. 16, 2006. p. 20-45.

THOMPSON, John. A Mídia e a modernidade: uma teoria social da mídia. Petrópolis/RJ, Vozes, 1995.

TODOROV, Tzvetan. Los abusos de la memória. Tradução Miguel Salazar. Barcelona: Paidos, $2000 \odot$. 
WEBER, Max. Ciência e política: duas vocações. Trad. de Leonidas Hegenberg e Octany Silveira da Mota. São Paulo: Cultrix, (01967.

WEBER, Max. . Economia e sociedade: fundamentos da sociologia compreensiva. Trad. Régis Barbosa e Karen E. Barbosa; revisão técnica Gabriel Cohn. $4^{\text {a }}$ ed. (reimpressão). Brasília: Ed. Universidade de Brasília, 2000. 